\title{
Arquitetura deposicional da barreira holocênica na porção meridional da Ilha de São Francisco do Sul, SC, Brasil
}

\author{
Marcelo BOGO ${ }^{1}$, Maria Cristina de SOUZA², Rodolfo José ANGULO², Eduardo Guimarães BARBOZA ${ }^{3}$ \\ \& Maria Luiza Correa da Camara ROSA ${ }^{3}$
}

1 Programa de Pós-graduação em Geologia, Universidade Federal do Paraná. BR-277, s/n, CEP 81531-970, Curitiba, PR, Brasil. E-mail: bogo.marcelo@gmail.com.

2 Laboratório de Estudos Costeiros, Departamento de Geologia, Universidade Federal do Paraná. BR-277, s/n, Centro Politécnico, Jardim das Américas, CEP 81531-970, Curitiba, PR, Brasil. E-mail: cristinasouza@ufpr.br, angulo@ufpr.br.

3 Centro de Estudos de Geologia Costeira e Oceânica, Instituto de Geociências, Universidade Federal do Rio Grande do Sul. Av. Bento Gonçalves, 9500, CEP 91.540-000, Porto Alegre, RS, Brasil. E-mail: eduardo.barboza@ufrgs.br, luiza.camara@ufrgs.br.

Recebido em 07/2014. Aceito para publicação em 09/2015.

Versão online publicada em 11/12/2015 (www.pesquisasemgeociencias.ufrgs.br)

\begin{abstract}
Resumo - 0 método geofísico do radar de penetração no solo (GPR) juntamente com sondagens utilizando um vibrotestemunhador permitiram caracterizar as fácies sedimentares e a arquitetura deposicional da porção holocênica da planície costeira da Ilha de São Francisco do Sul, litoral norte de Santa Catarina. A área de estudo foi dividida em dois blocos, norte e sul, segundo a arquitetura deposicional definida através da estratigrafia de radar. Os dados obtidos permitiram a caracterização dos ambientes de sedimentação praial, eólico, lagunar e estuarino nos radargramas. No bloco norte são interpretados refletores condizentes com a progradação da barreira, relacionada com a queda de nível do mar de 2,5 m nos últimos 5.000 anos. No bloco sul, os refletores mostram clara influência de sistemas de paleocanais e esporões arenosos no desenvolvimento da barreira, onde a progradação se desenvolveu sob a influência da dinâmica do paleoestuário da Babitonga.
\end{abstract}

Palavras-chave: radarfácies, estratigrafia, Planície Costeira, GPR.

\begin{abstract}
Depositional ARCHitecture of THE Holocene BARRIER IN SÃo Francisco IsLAND, SANTA CATARINA, BRAZIL. The geophysical method GPR (Ground Penetrating Radar) together with subsurface sampling with a vibrocore allowed to characterize the sedimentary facies and depositional architecture of the Holocenic portion of the Ilha de São Francisco do Sul coastal plain, located in the northern region of Santa Catarina State. The study area was divided into two distinct blocks, north and south, according to the sedimentary architecture defined by radar stratigraphy. The collected data allowed the characterization of beach, eolic, lagoon and estuarine depositional environments in the radargram profiles. The north block has reflectors consistent with barrier progradation during the sea level fall of $2.5 \mathrm{~m}$ in the last 5,000 years. At south block the reflectors show clear influence of paleochannels systems and spits in the barrier development, where the progradation occurred under the influence of the Babitonga paleoestuary dynamics.
\end{abstract}

Keywords: radar facies, stratigraphy, coastal plain, GPR.

\section{Introdução}

0 método geofísico do georradar (Ground Penetration Radar - GPR) vem sendo empregado com sucesso em diversos trabalhos nas planícies costeiras da região sul do Brasil (Fitzgerald et al., 2007; Fracalossi et al., 2010; Silva et al., 2010; Dillenburg et al., 2011; Barboza et al., 2009, 2011), proporcionando a aquisição de registros de alta re- solução da arquitetura deposicional dos depósitos quaternários.

A planície costeira da Ilha de São Francisco do Sul é formada por depósitos sedimentares do Pleistoceno e do Holoceno, modelados como uma superfície plana a suavemente ondulada (Anjos, 2010). Sua gênese está relacionada à progradação costeira associada à queda do nível relativo do mar após o máximo pós-glacial ocorrido há 
aproximadamente 5.000 anos. Esse sistema tem como feições marcantes os cordões litorâneos, associados aos depósitos eólicos, lagunares, fluviais e praiais. A barreira holocênica apresenta espessuras da ordem de 15 m e é constituída essencialmente por sedimentos arenosos inconsolidados, propiciando o emprego dos métodos aqui descritos para a definição dos elementos arquitetônicos e das fácies sedimentares, com o objetivo de caracterizar os ambientes sedimentares ativos durante os ciclos de construção da barreira.

\section{2 Área, materiais e métodos}

\section{1 Área}

A Ilha de São Francisco do Sul está localizada na porção setentrional do litoral do Estado de Santa Catarina, entre as coordenadas $48^{\circ} 29^{\prime}$ e $48^{\circ} 42^{\prime}$ de longitude Oeste, $26^{\circ} 27^{\prime}$ e $26^{\circ} 09^{\prime}$ de latitude Sul, e situada no Município de São Francisco do Sul (Fig. 1). A ilha possui comprimento de $35 \mathrm{~km}$ e largura de 16 km (IBGE, 2013). Sua área é de aproximadamente $270 \mathrm{~km}^{2}$. 0 presente estudo restringe-se ao sul da ilha, na localidade de Praia do Ervino, onde foram realizados levantamentos com o georradar e as sondagens com vibrotestemunhador.

A região norte do litoral de Santa Catarina pertence à zona climática subtropical temperada, com clima regional subtropical úmido, Cfa na classificação de Köeppen-Geiger (Peel et al., 2007).

Segundo Fedorova (2001), o clima regional é controlado por duas massas de ar oceânicas de caráter sinótico: o anticiclone tropical do Atlântico sul ou Alta Subtropical do Atlântico (AAS) e o Anticiclone Migratório Polar (AMP). As frentes frias de inverno originam-se da zona limítrofe entre estas duas massas de ar, promovendo variações na pressão atmosférica à medida que se movem.

Em São Francisco do Sul, a direção predominante dos ventos é do quadrante SW (22\%) seguido dos quadrantes NE e S, representando, respectivamente, 18 e $13 \%$ do registro para o ano de 2004 (Angulo et al., 2009). 0 clima de ondas da região apresenta predominância de incidência de ondulações (swell) de sudeste e leste, devido à orientação da linha de costa e aos efeitos de refração de ondas (Alves, 1996).

Na região, o regime é de micromarés, semidiurno, com amplitude média de 1,30 m e máxima de 1,90 m nas sizígias (BNDO, 2012). Durante a passagem dos sistemas frontais, a maré meteorológica pode alcançar, em média, $1 \mathrm{~m}$ (Trucollo, 1998).
A ilha é constituída por substrato de rochas gnáissicas e migmatitos do embasamento pré-cambriano e por sedimentos quaternários (Fig. 1), incluindo depósitos de origem continental e costeira (Horn Filho, 1997).

Os depósitos de origem continental encontram-se preferencialmente nas adjacências de elevações sustentadas por rochas do embasamento. Os depósitos costeiros incluem os de origem marinha, lagunar e eólica, que constituem a planície costeira, associados a depósitos de ambientes atuais, tais como os de planícies de maré, várzeas fluviais e campos de dunas ativos.

Os sedimentos constituintes das barreiras acumularam-se em torno de elevações do embasamento, constituídas por corpos granitóides do Terreno Paranaguá. Estes corpos graníticos, que se concentram na parte oeste da ilha, estão inseridos em faixa de orientação NE-SW, com cerca de 250 $\mathrm{km}$ de comprimento e largura média de $30 \mathrm{~km}$, que se estende desde São Francisco do Sul até o litoral sul do Estado de São Paulo. Esta faixa limita-se tectonicamente com as microplacas Luis Alves e Curitiba através das zonas de cisalhamento transcorrentes Palmital e Alexandra em sua porção meridional (Cury, 2009). Os gnaisses e gnaisses-migmatitos que ocorrem na ilha foram incluídos no Complexo São Francisco do Sul, suíte que constitui as rochas encaixantes para os corpos ígneos da Suíte Morro Inglês (Cury, 2009).

A barreira pleistocênica aflora na porção interior da planície, com altitude máxima de $16 \mathrm{~m}$ (Possamai et al., 2010). A barreira holocênica possui $15 \mathrm{~km}^{2}$ e altitude média de $4 \mathrm{~m}$. Segundo Anjos (2010) esta barreira é caracterizada por sedimentos marinhos e ocorre associada a uma planície paleolagunar, também de idade holocênica; é composta por areia quartzosa fina a média, com teores variáveis de minerais pesados (Anjos, 2010). Enriquecimento epigenético de matéria orgânica, ligado a processos pedogenéticos e flutuações do nível freático, ocorre nos sedimentos de ambos os sistemas de barreiras.

Zular (2011) através de datação pelo método de luminescência opticamente estimulada com protocolo SAR (Single Aliquote Regenerative Dose) obteve idade máxima para os cordões litorâneos da barreira holocênica de $4.914 \pm 0.475$ anos AP.

Acima dos depósitos praiais ocorrem sedimentos eólicos na parte leste da ilha, distribuídos ao longo de faixa de $5,3 \mathrm{~km}^{2}$ e largura entre $50 \mathrm{~m}$ e $1.060 \mathrm{~m}$. Os depósitos eólicos apresentam-se como dunas ativas e vegetadas ou estabilizadas, onde predominam areias finas, quartzosas e arredondadas (Anjos, 2010). Zular (2011) obteve idade má- 


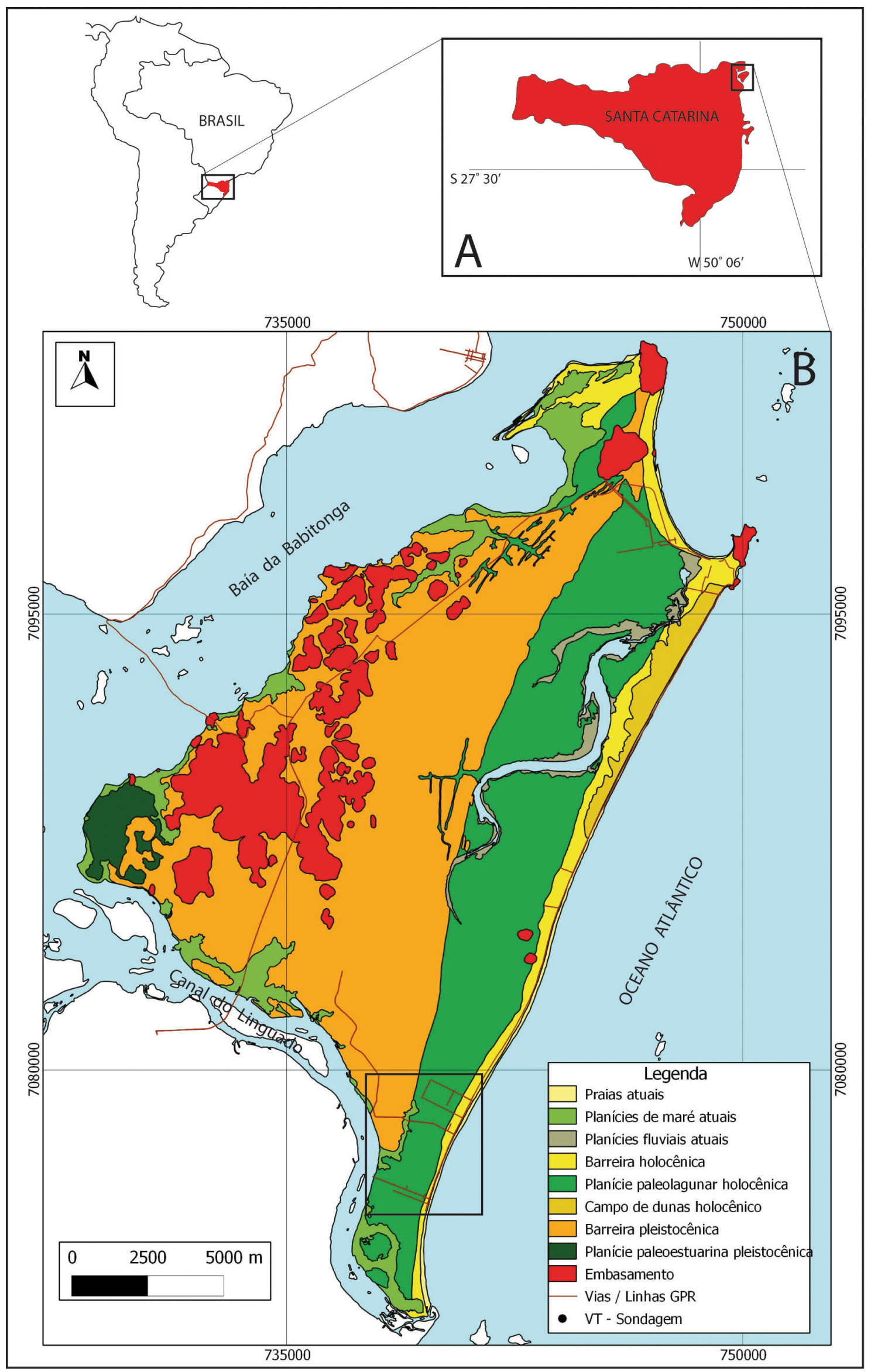

Figura 1. Localização da área de estudo. A) Ilha de São Francisco do Sul, no Estado de Santa Catarina; B) Mapa geológico (modificado de Anjos, 2010). 
xima para os depósitos eólicos de 1.891 \pm 155 anos A.P.

\subsection{Materiais e métodos}

Para a realização deste estudo foram analisados e interpretados sete radargramas obtidos pelo método do georradar (Fig. 2). Estes foram integrados com registro de quatro testemunhos de sondagem, a partir dos quais foram descritas as fácies sedimentares.

Os radargramas foram obtidos em março de 2009 pelo coletor SIR-3000 da GSSI ${ }^{\mathrm{TM}}$ (Geophysical Survey Systems, Inc.) e com antena de frequência central de $200 \mathrm{MHz}$, registrando até $12 \mathrm{~m}$ de profundidade, acoplada a sistema GNSS (Global Navigation Satellite System) pós-processado. O arranjo empregado foi o Common off-set, sendo que durante a aquisição foram utilizados filtros de frequência e ganhos. A constante dielétrica (10) escolhida para o levantamento representa a velocidade intervalar média de $0,09 \mathrm{~m} / \mathrm{hs}$ (Davis \& Annan, 1989).

Os registros de campo selecionados foram processados e interpretados através do programa RADAN $^{\mathrm{TM}}$ 6.6. Nesta etapa foram aplicados filtros passa-banda (IIR), range-gain e background removal (FIR) para remoção de ruído e ganho de sinal. Para a correção topográfica foram utilizados os dados obtidos pelo método DGPS (GNSS Diferencial). Para a interpretação dos dados foram aplicados os conceitos de estratigrafia de radar propostos por
Jol \& Bristow (2003) e Neal (2004).

Segundo Neal (2004), os elementos presentes nos radargramas podem ser divididos em superfícies de radar, radarfácies e unidades de radar. As radarfácies são conjuntos de refletores análogos contidos ou delimitados por superfícies de descontinuidades, e são caracterizados descritivamente por sua forma, mergulho, continuidade e relações com reflexões adjacentes (onlap, downlap, toplap, truncamento erosivo).

Os critérios para a interpretação das principais superfícies de radar foram definidos pela terminação dos refletores em relação às superfícies de maior continuidade lateral.

Através das características observadas nos radargramas analisados, a área de estudo foi dividida em dois domínios sedimentares distintos, denominados blocos norte e sul (Fig. 2).

Foram executadas sondagens com vibrotestemunhador visando alvos em que a profundidade máxima alcançada pela sondagem (em torno de 6 m) pudesse interceptar o máximo de estruturas visíveis nos radargramas. As coordenadas para os furos de sondagem foram extraídas diretamente dos arquivos obtidos pelo método GNSS durante o levantamento conjunto com o georradar.

A descrição das fácies seguiu os critérios estabelecidos em Walker (1992) e Clifton (2006), incluindo textura, composição, estruturas sedimentares, espessura, continuidade lateral e contatos. A nomenclatura das fácies foi adaptada de Miall (2006).

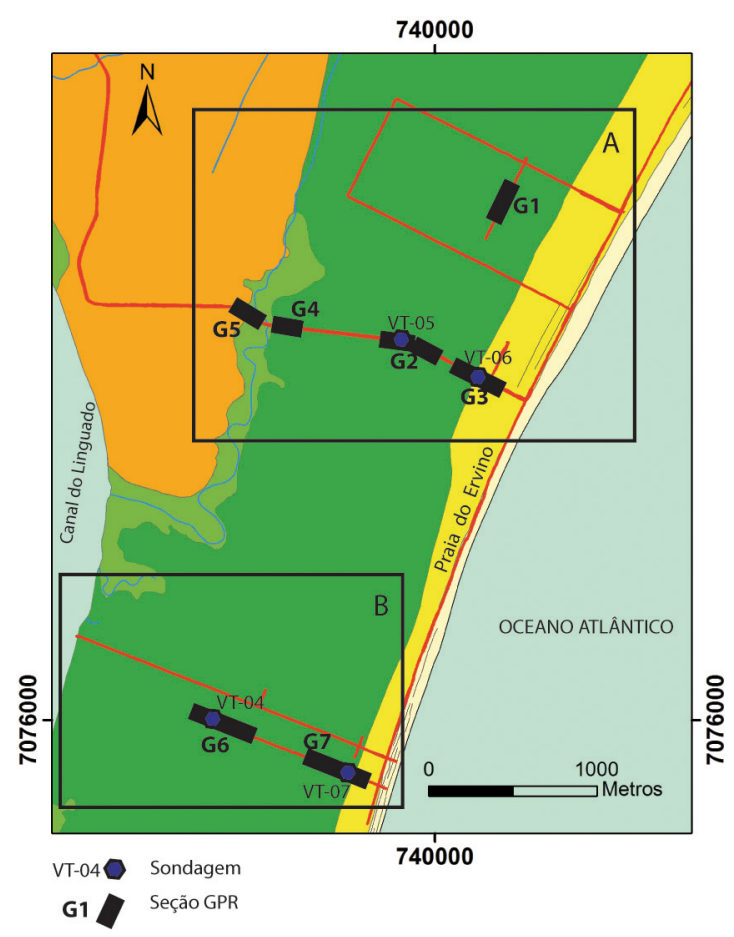

Figura 2. Investigações na área de estudo: blocos norte (A) e sul (B), com localização dos levantamentos de georradar (seções G1, G2, G3, G4, G5, G6 e G7) e sondagens com vibrotestemunhador (VT04, VT05, VT06 e VT07). 


\section{Resultados}

\subsection{Fácies sedimentares}

Nas sondagens foram identificadas seis fácies sedimentares (Fig. 3), constituídas predominantemente por areia fina, com frações subordinadas de areia muito fina, média e grossa. Argila e silte ocorrem em horizontes próximos à superfície, associados à matéria orgânica, ou em pequenas proporções em algumas fácies.

\subsubsection{Areia com laminação cruzada acanalada (St)}

A fácies St (Fig. 3A) é constituída por areia muito fina a fina, moderadamente selecionada com intercalações ou lentes de areia média com espessura variando de 5 a $10 \mathrm{~cm}$. Apresenta lâminas com concavidade para cima, muito incipientes. Em alguns pontos observam-se bioturbações e lâminas muito finas de matéria orgânica nas calhas das estruturas.

\subsubsection{Areia com laminação cruzada planar (Sp)}

A fácies Sp (Fig. 3B) apresenta-se em sets em forma de cunha com ângulos entre 10 e 15 graus. Constituída por areia fina a média, moderadamente selecionada, observando-se a presença de icnofósseis Ophiomorpha sp e lâminas de matéria orgânica.

\subsubsection{Areia maciça $(\mathrm{Sm})$}

A fácies Sm (Fig. 3C) é constituída por areia muito fina a fina, essencialmente quartzosa com proporções variáveis de matéria orgânica dispersa. Grãos moderadamente a bem selecionados e cor variando de esverdeada a bege. Ocorrem marcas de raízes e enriquecimento epigenético por óxidos e hidróxidos de ferro em alguns pontos.

\subsubsection{Areia com laminação cruzada de baixo ângulo (Sli)}

A fácies Sli (Fig. 3D) é constituída por areia fina a média, moderadamente selecionada. Apresenta lâminas muito incipientes com truncamento
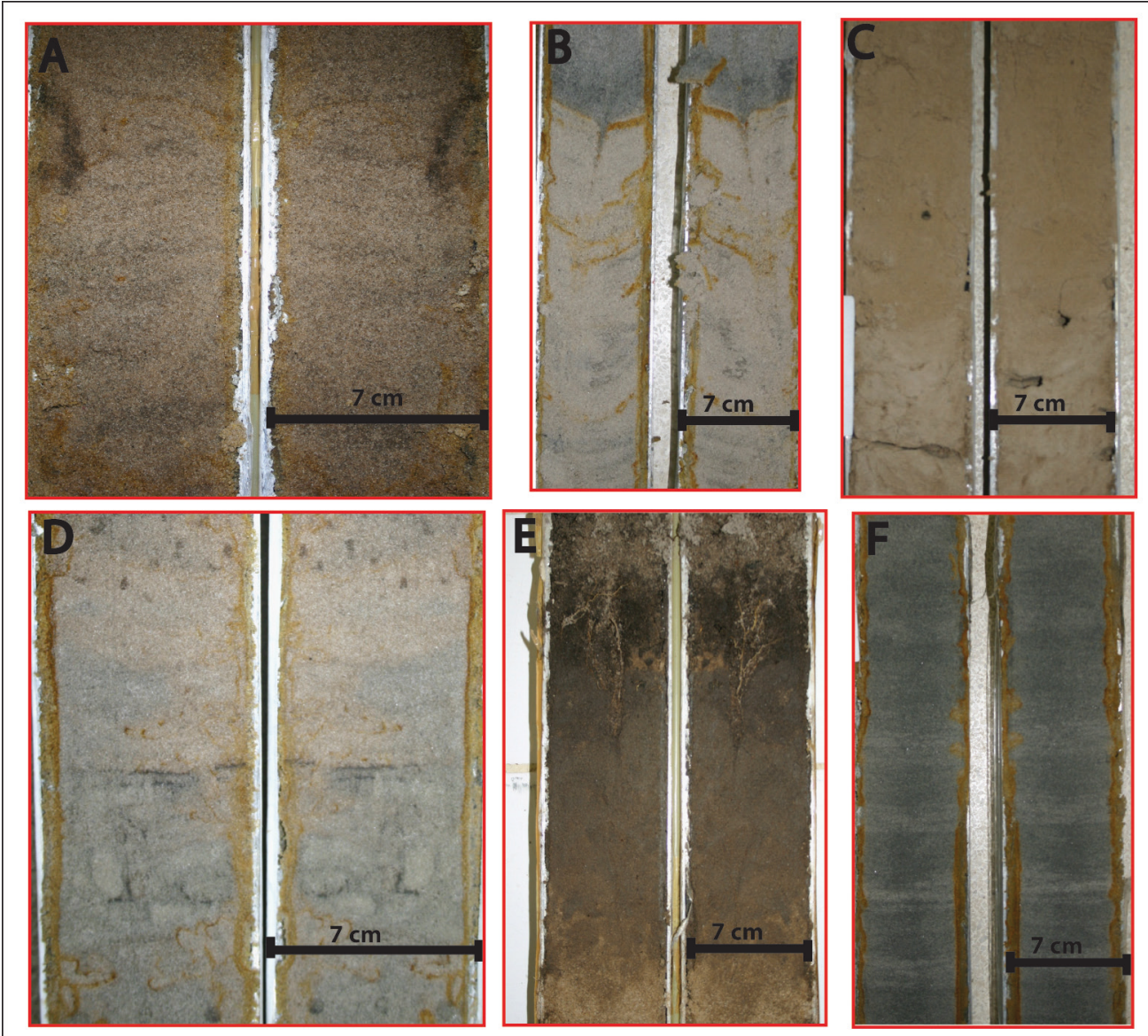

Figura 3. Fácies sedimentares. A) St: Areia com laminação cruzada planar, B) Sp: Areia com laminação cruzada acanalada, C) Sm: Areia maciça, D) Sli: Areia com laminação cruzada de baixo ângulo, E) Fm: Lama maciça, F) Sh: Areia com laminação plano-paralela. 
em baixo ângulo (1-5). Ocorrem pequenas camadas de até $3 \mathrm{~cm}$ de areia média a grossa associadas, intercaladas em ritmicidade.

\subsubsection{Lama maciça (Fm)}

A fácies Fm (Fig. 3E) é constituída por sedimentos argilosos com proporções variáveis de matéria orgânica e de areia muito fina a fina e cor variando de marrom ou cinza escuro a preto; ocorre nos horizontes superiores, constituída predominantemente por argila e areia muito fina, com fração silte subordinada. Presença abundante de matéria orgânica, principalmente restos vegetais.

\subsubsection{Areia com laminação plano-paralela (Sh)}

A fácies Sh (Fig. 3F) é constituída por areia muito fina a média essencialmente quartzosa, com grãos subarredondados e moderadamente selecionados. Apresenta lâminas horizontais a sub-horizontais. Devido ao diâmetro reduzido do testemunho, é de difícil distinção em relação à facies Sli.

Ocorrem associadas a esta fácies pontuações de matéria orgânica e bioturbações não figurativas. Finas lâminas de argila (mud drapes) foram observadas pontualmente.

\subsection{Radarfácies e superfícies limitantes}

Três grupos de radarfácies foram definidos: refletores oblíquos, sub-horizontais e irregulares (Fig. 4). Enquanto as radarfácies oblíquas e subhorizontais estão relacionadas diretamente à geometria dos estratos sedimentares, as radarfácies irregulares, com hipérboles, de aspecto opaco ou de alto contraste, podem estar associadas a variações composicionais ou texturais.

Estes refletores apresentam-se em downlap sobre superfícies limitantes associadas a descontinuidades de caráter erosivo, ou de hiato deposicional entre as sequências sedimentares. Estas superfícies são em geral horizontalizadas, irregulares, e com forte contraste, podendo também truncar refletores subjacentes (Fig. 5). Feições associadas à escavação de paleocanais ocorrem incisas nestas superfícies.

A superfície Sf1-Dc destaca-se em todas as seções analisadas por sua grande amplitude e continuidade, ocorrendo entre 5 e $15 \mathrm{~m}$ de profundidade. Refletores abaixo desta superfície exibem progradação para leste e são truncados pela superfície Sf1-Dc. As superfícies de radar Sf2-Dc, Sf3-Dc e Sf4-Dc são subhorizontais, lateralmente contínuas, separando conjuntos de fácies geneticamente relacionadas.

\subsection{Arquitetura deposicional e fácies sedimentares}

Os radargramas apresentam na porção superficial um horizonte com espessura média de $0,8 \mathrm{~m}$ e refletores de contraste variável, associado a solos, lençóis arenosos ou aterros, como o da figura 6. Nos trechos dos radargramas mais próximos à linha de costa, esse horizonte corresponde a dunas frontais.

Os depósitos associados aos cordões litorâneos foram caracterizados por refletores ondulados (radarfácies Fs-On), definidos por cristas e por cavas descontínuas e de baixo contraste. Os depósitos eólicos associados às dunas frontais foram caracterizados por refletores planos (Fs-Tbb) ou acanalados (Fs-Ce) formando estratificações cruzadas com truncamentos na base.

No bloco norte os depósitos praiais foram caracterizados por refletores tabulares de baixo ângulo e alto contraste em downlap sobre uma superfície erosiva (Sf1-Dc), inclinada para leste (Fig. 7). Estes refletores (radarfácies Fs-Tbb), de grande continuidade lateral, apresentam ondulações de grande comprimento de onda $(\sim 35 \mathrm{~m})$ e pequena amplitude $(\sim 0,3 \mathrm{~m})$, com truncamentos caracterizados por mudanças de ângulo na estratificação.

0 testemunho VT-05 é constituído por areia fina com enriquecimento epigenético e laminações tabulares plano-paralelas de baixo ângulo (Fig. 8).

A estratificação cruzada de baixo ângulo (2$5^{\circ}$ ) está relacionada aos processos de espraiamento no ambiente de face praial; refletores truncando estas estruturas com mais alto ângulo, em torno de $5-10^{\circ}$, podem estar relacionados às mudanças na inclinação da face praial durante eventos de tempestade. Na região já próxima a praia, a radarfácies Fs-Tbb encontra-se a 2 m de profundidade, com 6 m de espessura (Fig. 9).

Subjacente aos depósitos praiais, é notável a ocorrência de uma espessa camada de sedimentos representados principalmente por refletores lenticulares côncavo-convexos sub-horizontais (Fs-Lt), com refletores sigmóides (Fs-Sg) inclinados para o mar (onshore). Este intervalo com espessura de até $6 \mathrm{~m}$ foi interpretado como correspondente a sedimentos da face litorânea. Os intervalos definidos pela ocorrência de refletores sigmóides ocorrem na base da sequência de face litorânea, e estão confinados por corpos alongados de dezenas de metros e espessuras de 1 a $2,5 \mathrm{~m}$, com formas sigmoides, com mergulho de 6 a $8^{\circ}$, indicando progradação para oeste, em downlap na Sf1-Dc e toplap em Sf2-Dc. Estas macroformas foram interpreta- 


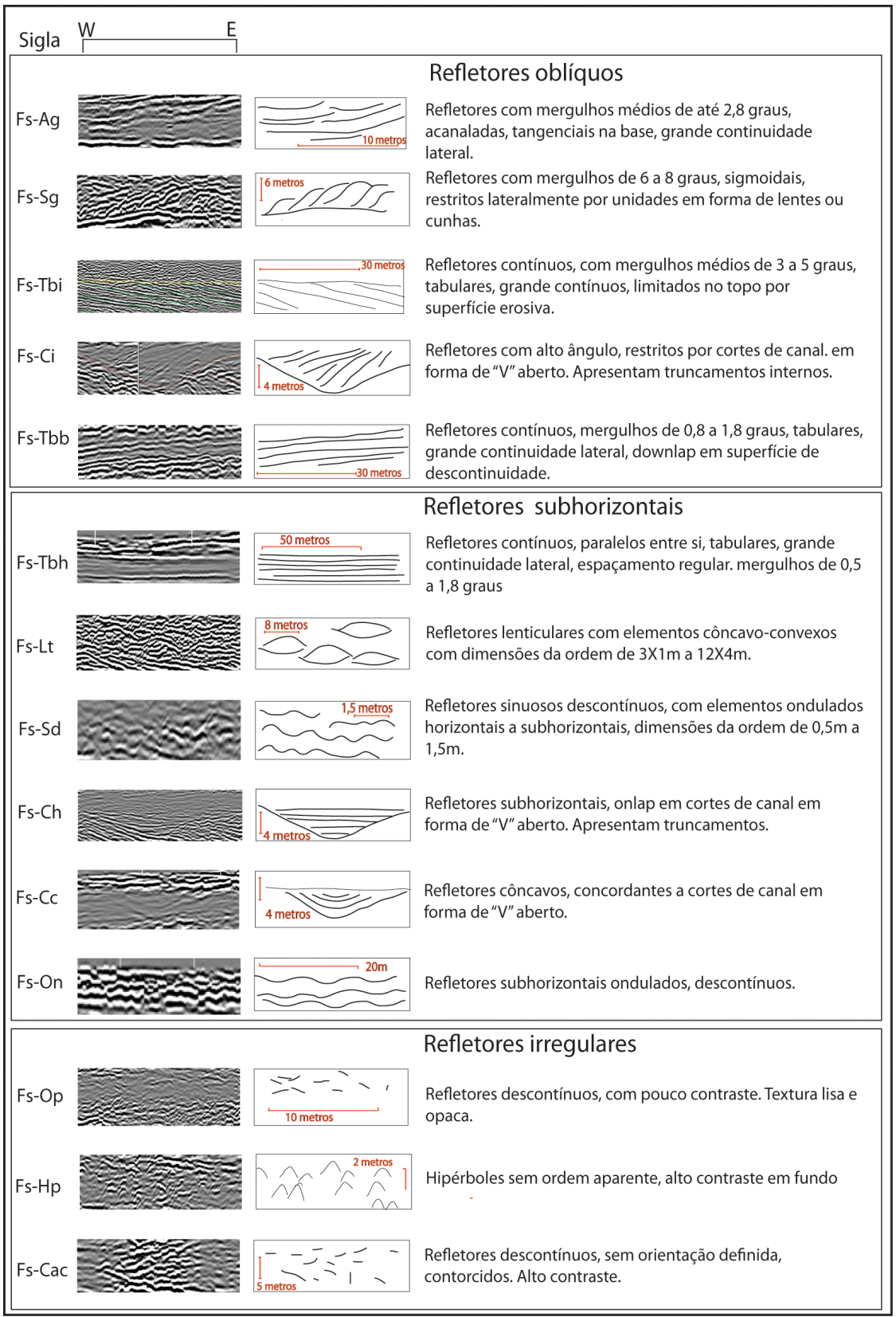

Figura 4. Padrões das radarfácies agrupadas segundo sua forma, mergulho e continuidade lateral.

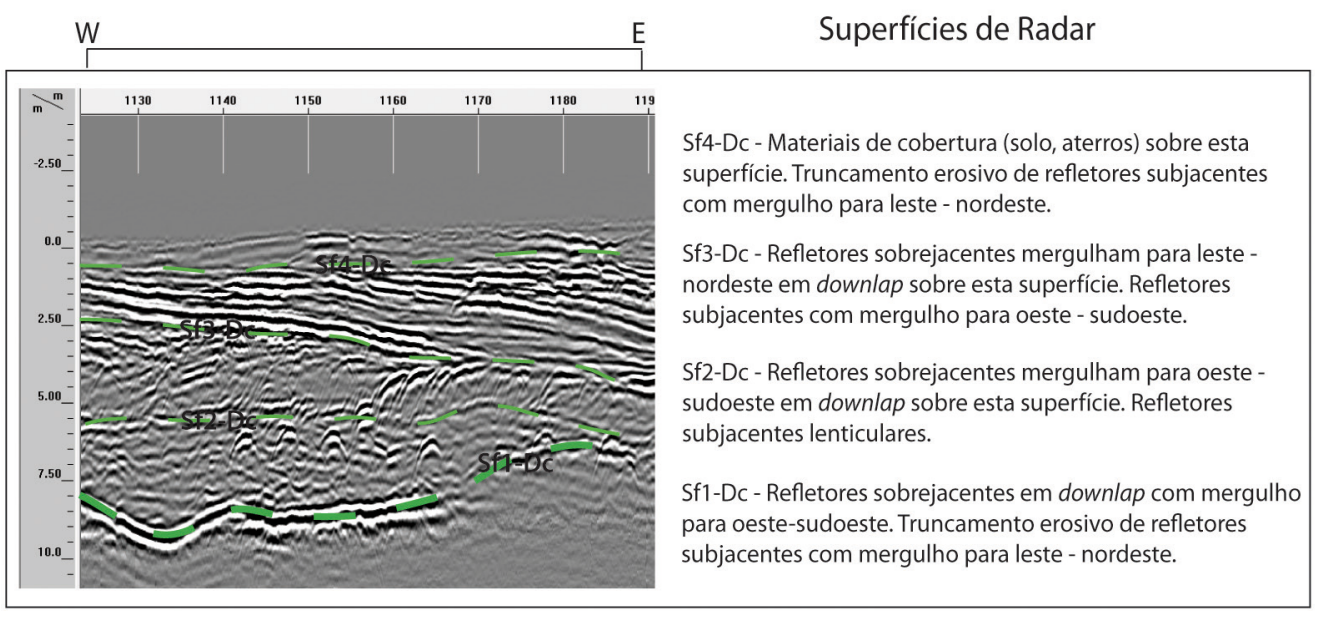

Figura 5. Superfícies de radar na seção-tipo G2. 
das como barras submersas ou sand waves em ambiente de face litorânea média a inferior.

0 furo de sondagem VT-6, executado na extremidade leste da seção G2 (Fig. 10) permitiu a recuperação de material constituído predominantemente por areia fina com laminação cruzada de baixo ângulo, com intercalação de lâminas e lentes de areia grossa e tubos Ophiomorpha sp., atribuídos a Callichirus major. A porção superior do testemunho é interpretada como sendo de ambiente eólico.
Na seção G1, paralela à linha de costa, os refletores tabulares que representam a regressão da linha de costa apresentam leve mergulho para norte, sugerindo que além de se deslocar no sentido do oceano, a barreira se deslocou também para o norte, possivelmente sob efeito da deriva litorânea. Esporões (Fs-Sg) com progradação para sul, identificados nesta seção, podem ser o resultado de inversões no sentido de deriva durante a progradação (Fig. 11).

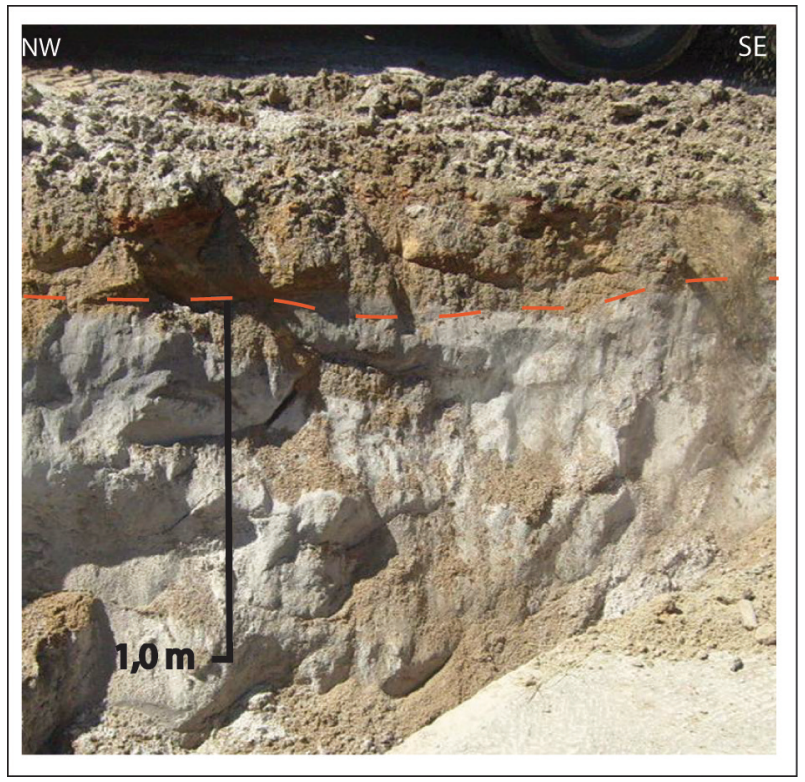

Figura 6. Corte de estrada na seção G3, próximo ao VT-06. Em traços descontínuos o contato do aterro acima dos depósitos arenosos da barreira holocênica.

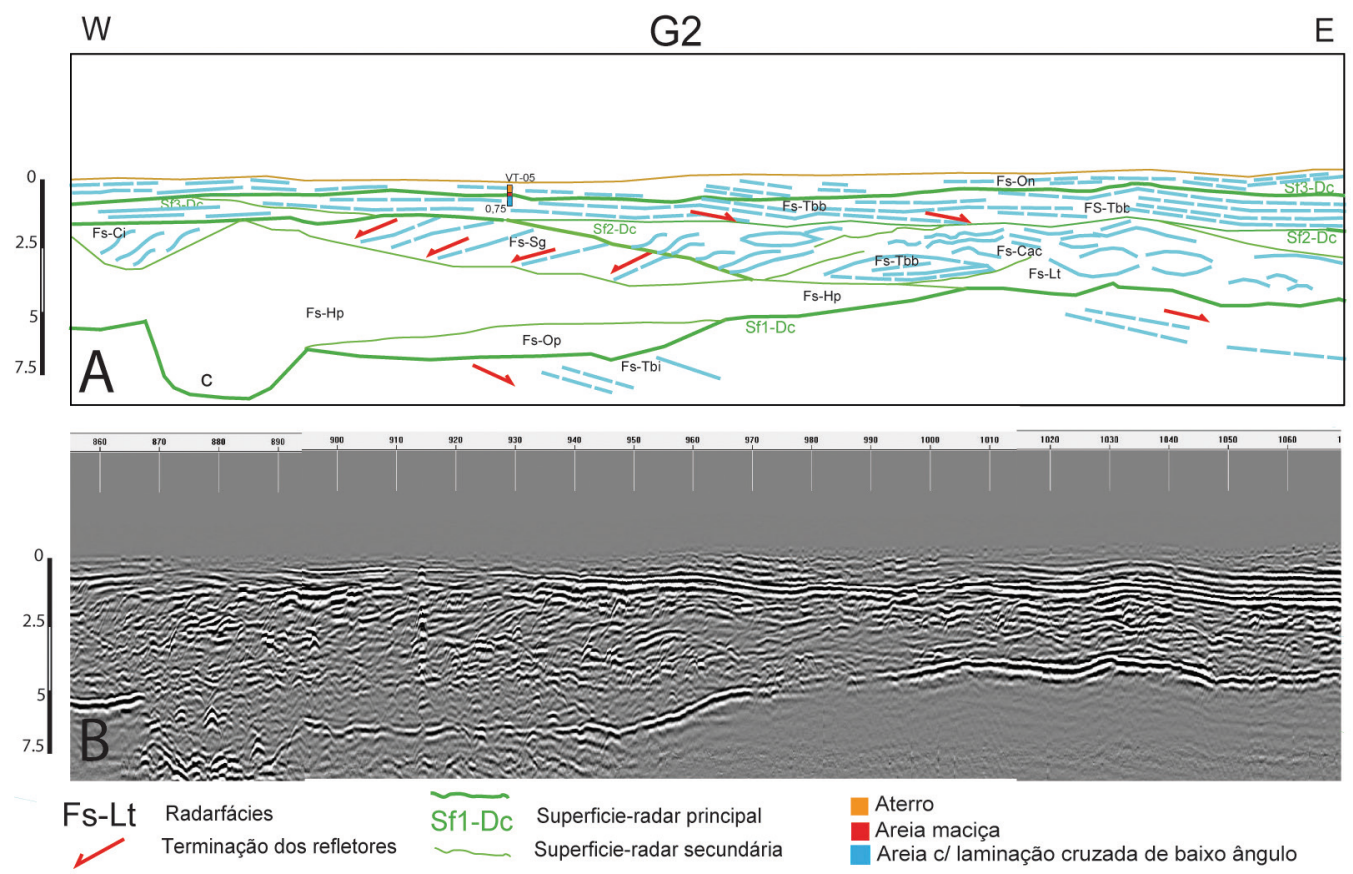

Figura 7. Seção G2. A) Interpretação dos refletores e furo de sondagem VT-05; B) Radargrama. Notar canal inciso (c) na superfície Sf1-Dc. 


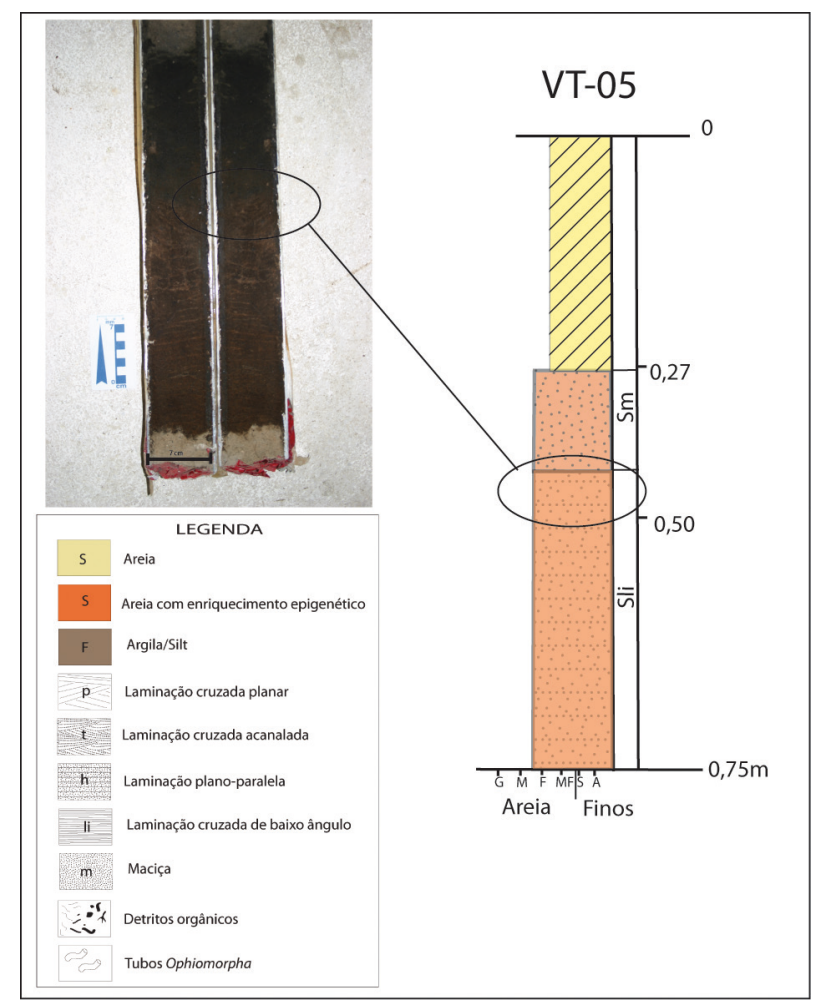

Figura 8. Perfil do VT-05 com as fácies sedimentares e fotografia do testemunho.

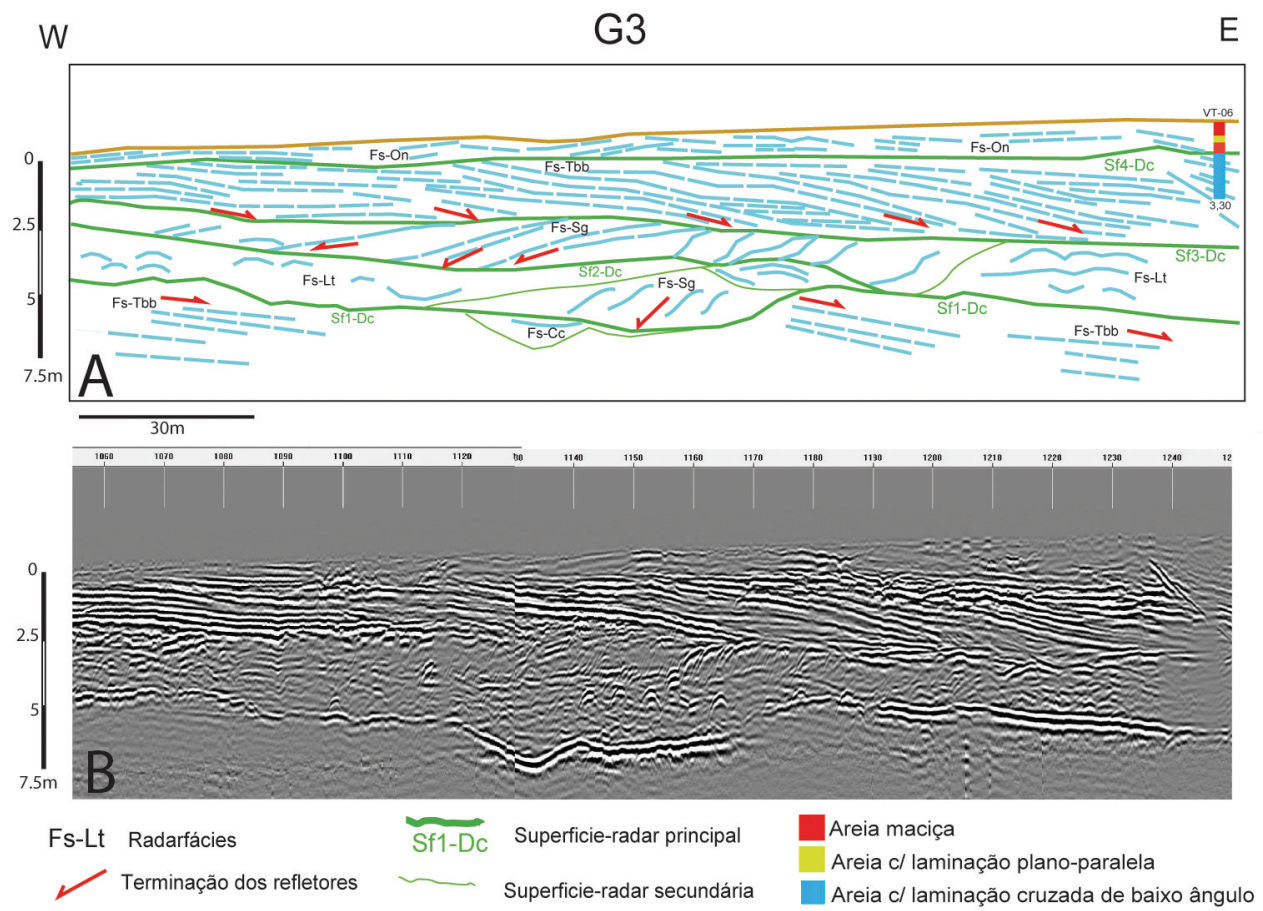

Figura 9. Seção G3. A) Interpretação dos refletores e furo de sondagem VT-06; B) Radargrama.

No bloco sul os refletores relacionados à progradação da barreira são descontínuos e com baixo contraste. Próximo ao Canal do Linguado (extremo oeste da seção G6), mapeada como planície paleolagunar holocênica (Anjos, 2010), pode-se observar que os refletores de grande amplitude de sinal da radarfácies Fs-Tbb e Fs-Tbi apresentam-se com ampla continuidade lateral, em forma de cunha com truncamentos internos, e em downlap de muito baixo ângulo, com mergulho para oeste (Fig. 12). Abaixo deste horizonte, observa-se um corpo alongado sigmoidal com progradação também para oeste. Na base da sequência, refletores lenticulares da radarfácies Fs-Lt ocorrem em horizonte de $5 \mathrm{~m}$ de espessura sobre a superfície Sf1-Dc.

No testemunho VT-4 (Fig. 13), localizado no extremo oeste da seção, ocorrem sedimentos are- 
nosos com estratificação cruzada planar e estratificação cruzada de baixo ângulo, com presença de matéria orgânica em lâminas e associada a tubos Ophiomorpha sp. Nos radargramas são visíveis estruturas côncavas interpretadas como paleocanais escavados na parte superior destes depósitos praiais (Fig. 14). Os paleocanais apresentam morfologia com geometrias em forma de "V" ou " $U$ " aberto, com 0,5 a $4 \mathrm{~m}$ de profundidade e preenchimentos com os padrões Fs-Ch, Fs-Ci e Fs-Cc. Os padrões de reflexões com hipérboles, como na ra- darfácies Fs-Hp podem estar relacionados à ocorrência de concentrações de clastos de argila, conchas ou cascalho nos paleocanais. Na extremidade leste da seção, no VT-07 (Fig. 15), a associação de fácies inclui além das estratificações cruzadas planares e de baixo ângulo, estratificações cruzadas acanaladas na base do testemunho. Ocorrem também Ophiomorpha sp. Esta associação de fácies pode estar associada a um ambiente de maior energia, como o de pé de praia ou face litorânea superior.

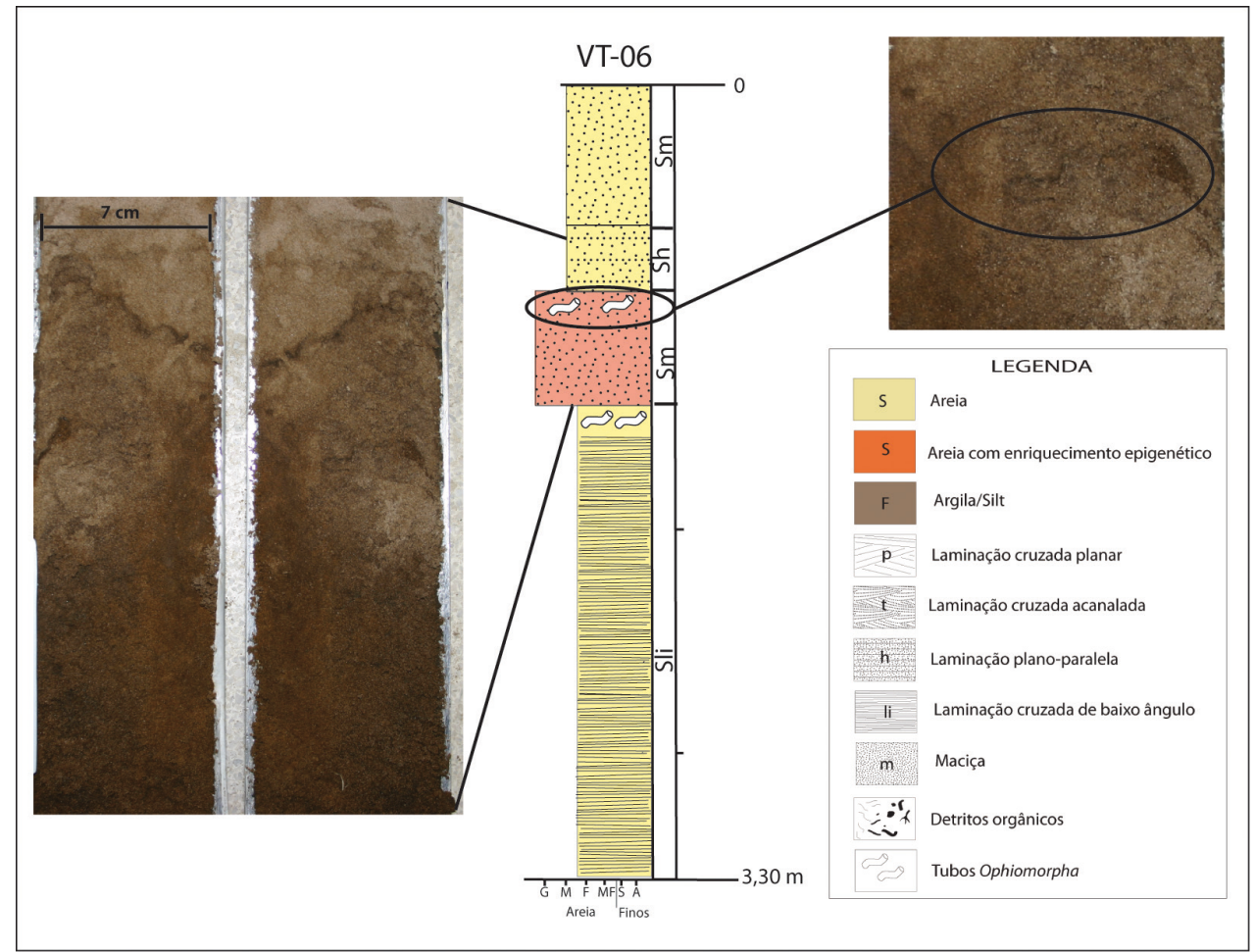

Figura 10 - Perfil do VT-06 com as fácies sedimentares e fotografia do testemunho (no detalhe Ophiomorpha sp.).

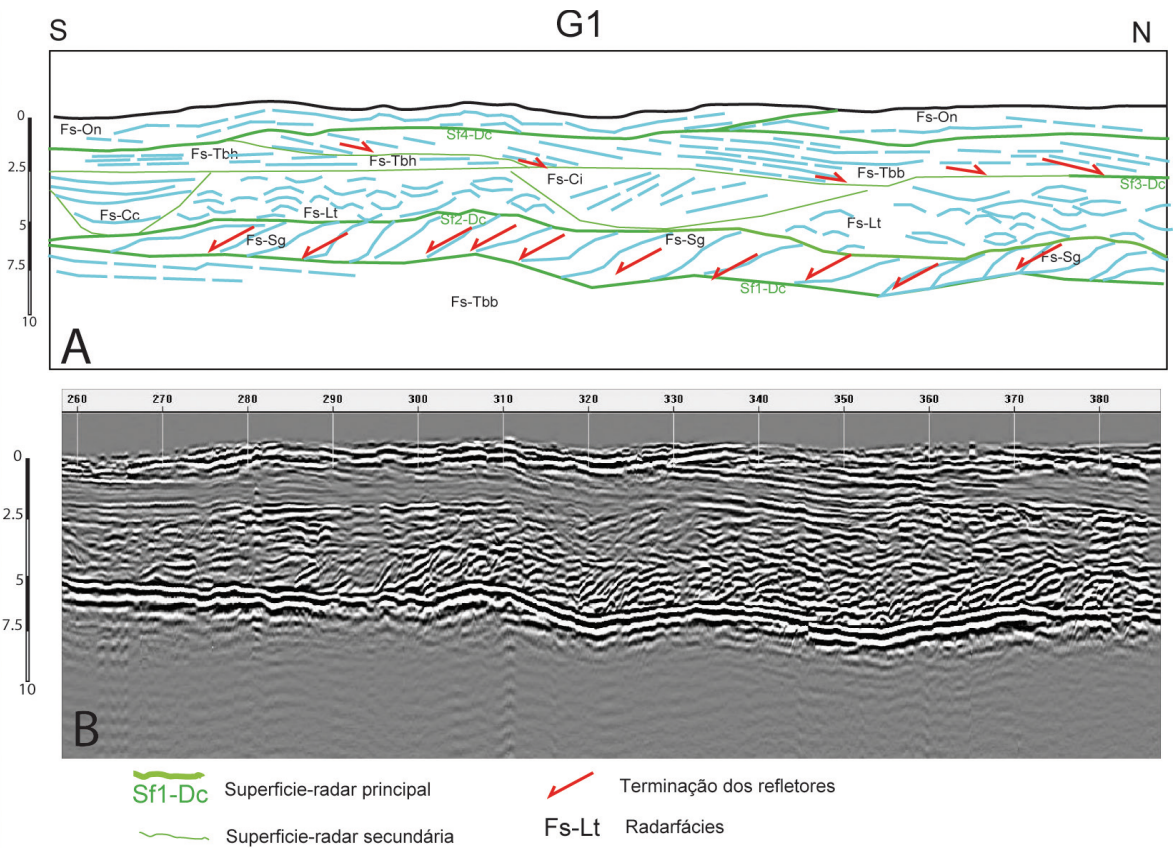

Figura 11. Seção G1. A) Interpretação dos refletores; B) Radargrama. 


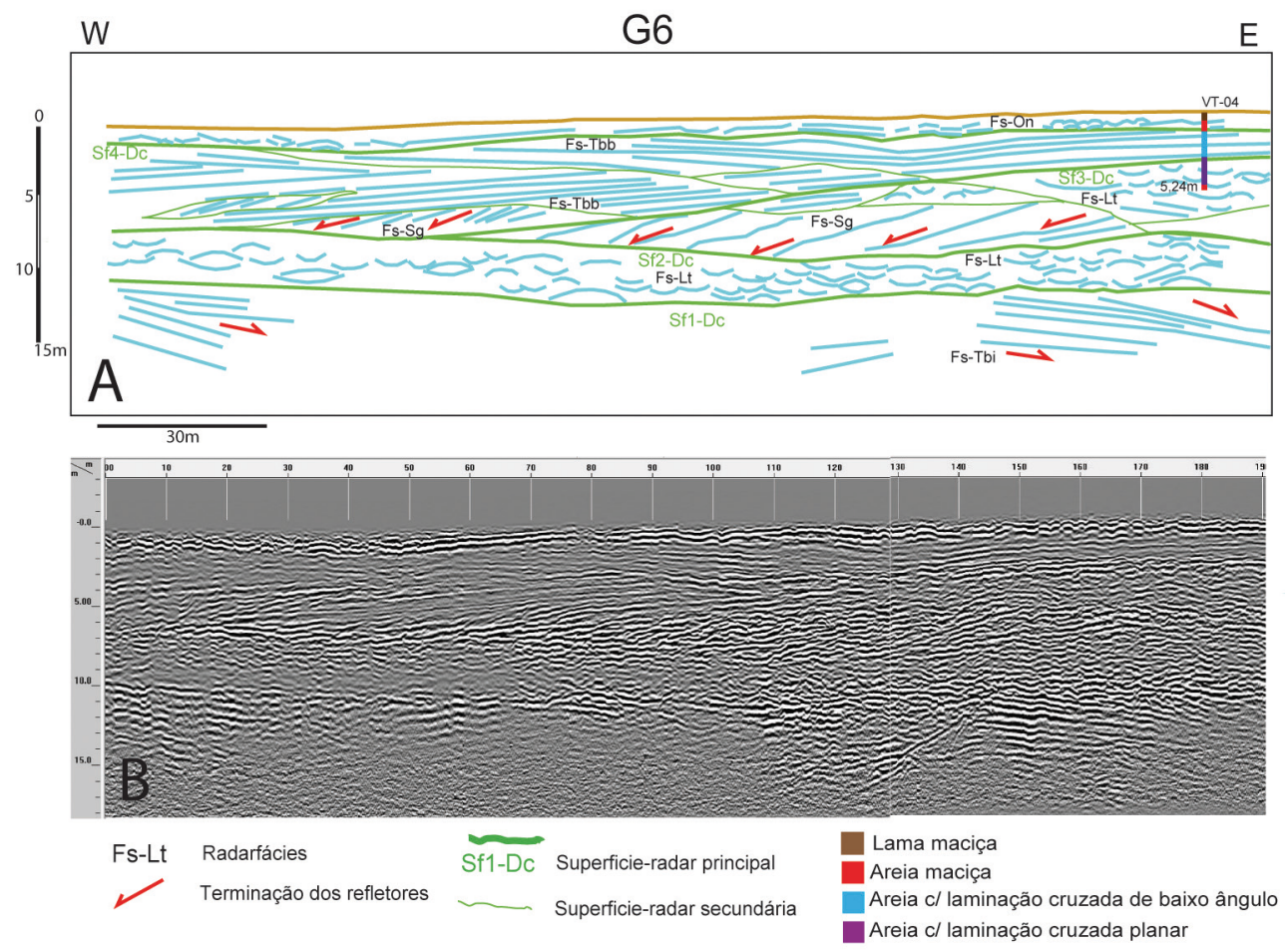

Figura 12. Seção G6. A) Interpretação dos refletores e furo de sondagem VT-04; B) Radargrama.

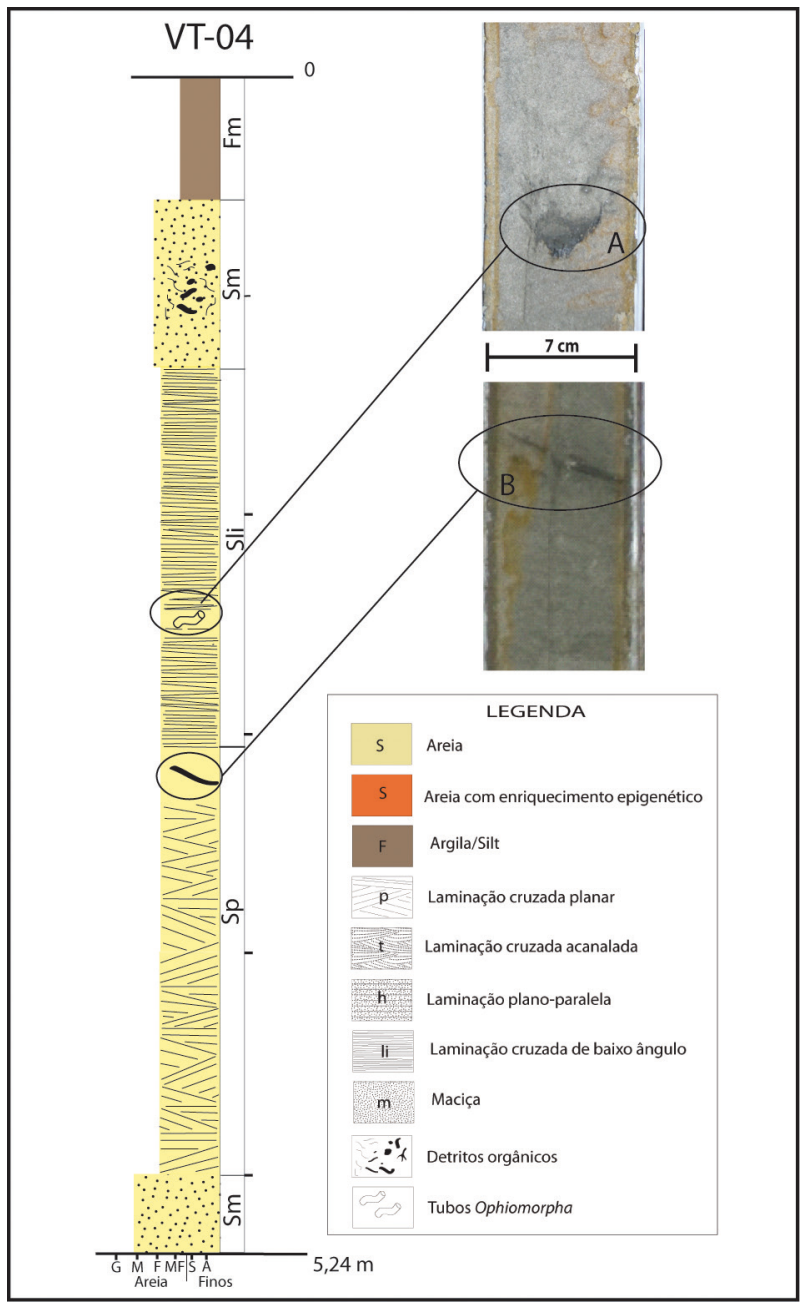

Figura 13. Perfil do VT-04 com as fácies sedimentares e fotografia do testemunho. Nos detalhes, concentrações de argila com matéria orgânica associada a tubos de Ophiomorpha sp. (A) e em lâminas (B). 

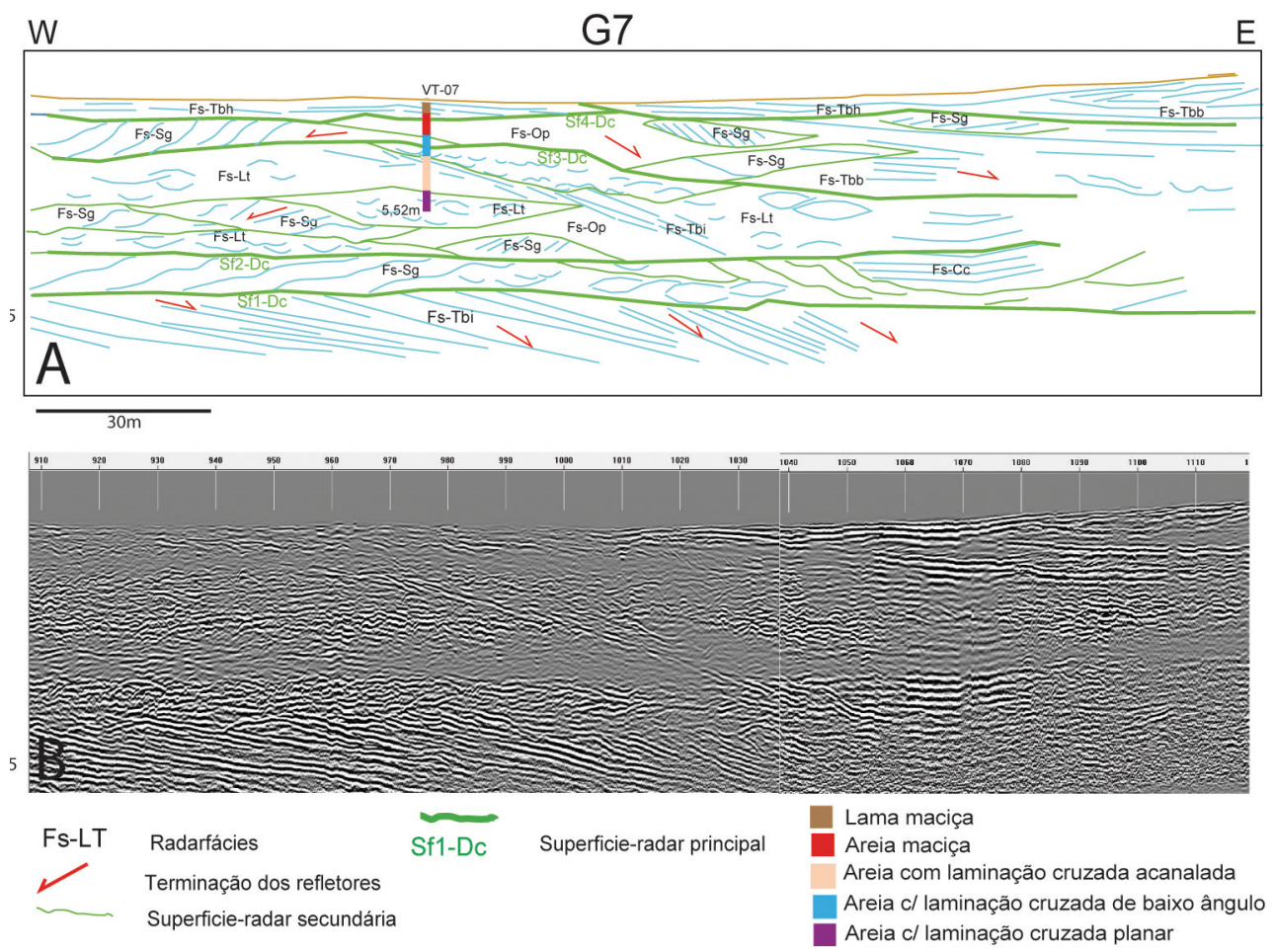

Figura 14. Seção G7. A) Interpretação dos refletores e furo de sondagem VT-07; B) Radargrama.

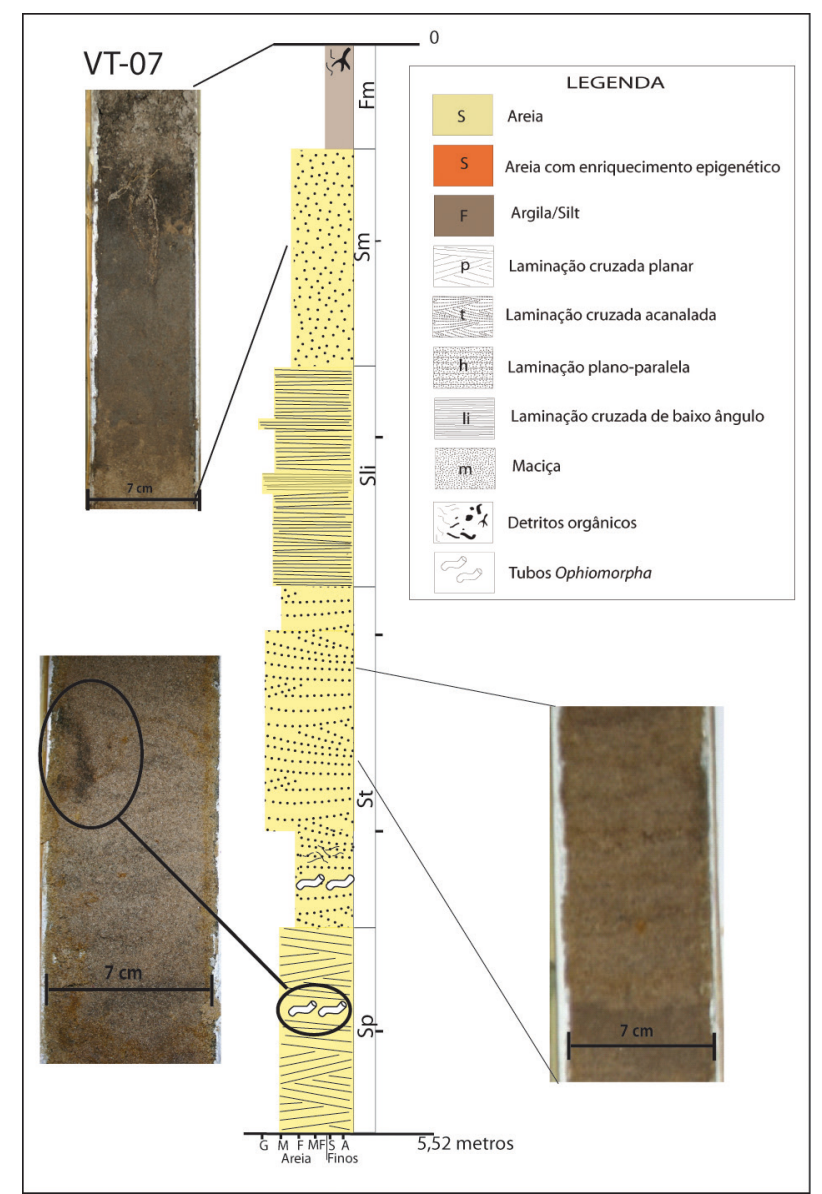

Figura 15. Perfil do VT-07 com as fácies sedimentares e fotografia do testemunho. Nos detalhes, estratificação cruzada acanalada e parte de tubo Ophiomorpha sp. atribuído a Callichirus major. 


\section{Discussão}

A superfície mais profunda identificada (Sf1-Dc) nos radargramas ocorre nas duas áreas estudadas, com características similares de amplitude dos refletores, geometria e caráter erosivo em relação às estruturas sotopostas, que por sua vez indicam progradação contínua, com diferenças em relação à profundidade, de $\sim 6 \mathrm{~m}$ no bloco norte $\mathrm{e} \sim 10 \mathrm{~m}$ no bloco sul. Esta superfície pode corresponder à discordância gerada durante a última regressão marinha do Pleistoceno. Sobre esta ocorrem refletores em downlap na sequência que se desenvolveu posteriormente. Foram identificados nos radargramas paleocanais escavados (vales incisos) sobre esta superfície. Angulo et al. (2009) identificaram superfície com padrão similar, na planície costeira paranaense, correlacionando-a ao substrato pleistocênico.

Pôde-se definir o contato entre a unidade pleistocênica e os sedimentos paleolagunares holocênicos (Fig. 16), limite que coincide com os indicados nos mapas geológicos da região (Martin et al., 1988; Horn Filho, 1997; Anjos, 2010).

A espessura da barreira holocênica varia de 3 a $5 \mathrm{~m}$ em sua porção interior, e de 15 a $18 \mathrm{~m}$ na parte mais próxima à linha de costa. No bloco norte, a barreira apresenta padrões que indicam a sua progradação, provavelmente relacionada à descida do nível do mar após o máximo holocênico (Angulo et al., 2006), com sobreposição de fácies de subambientes mais rasos de antepraia sobre as fácies mais profunda da face litoral média/inferior.

As fácies arenosas associadas ao ambiente de face praial, constituídas por areia fina, apresentam lentes de areia média a grossa, sugerindo eventos de maior energia atuando durante a progradação da barreira.

No bloco sul, os refletores que progradam para oeste, na região próxima às margens do Canal do Linguado, correspondem a depósitos associados a um paleoambiente de praia lagunar/ estuarina durante fase regressiva, o que concorda com a associação de fácies observada no VT-04. Os radargramas mostram ainda que a estratificação plano-paralela de baixo ângulo (Fs-Tbb), associada à progradação da barreira para leste, apresenta intensa perturbação por estruturas de corte e preenchimento de canais. Barboza et al. (2011) consideram que a evolução da barreira holocênica se deu sob influência de mudanças na geometria e dinâmica da desembocadura do Canal do Linguado. A ocorrência dos paleocanais neste setor evidencia a maior influência dos processos estuarinos, principalmente marés. 0 sedimento fino rico, em matéria orgânica na parte superior dos testemunhos, pode corresponder a uma paleolaguna rasa ou a canais estuarinos em fase de abandono. Sedimentos arenosos intercalados com os finos podem estar associados a depósitos de leques de sobrelavagem ou a depósitos de planícies de maré.
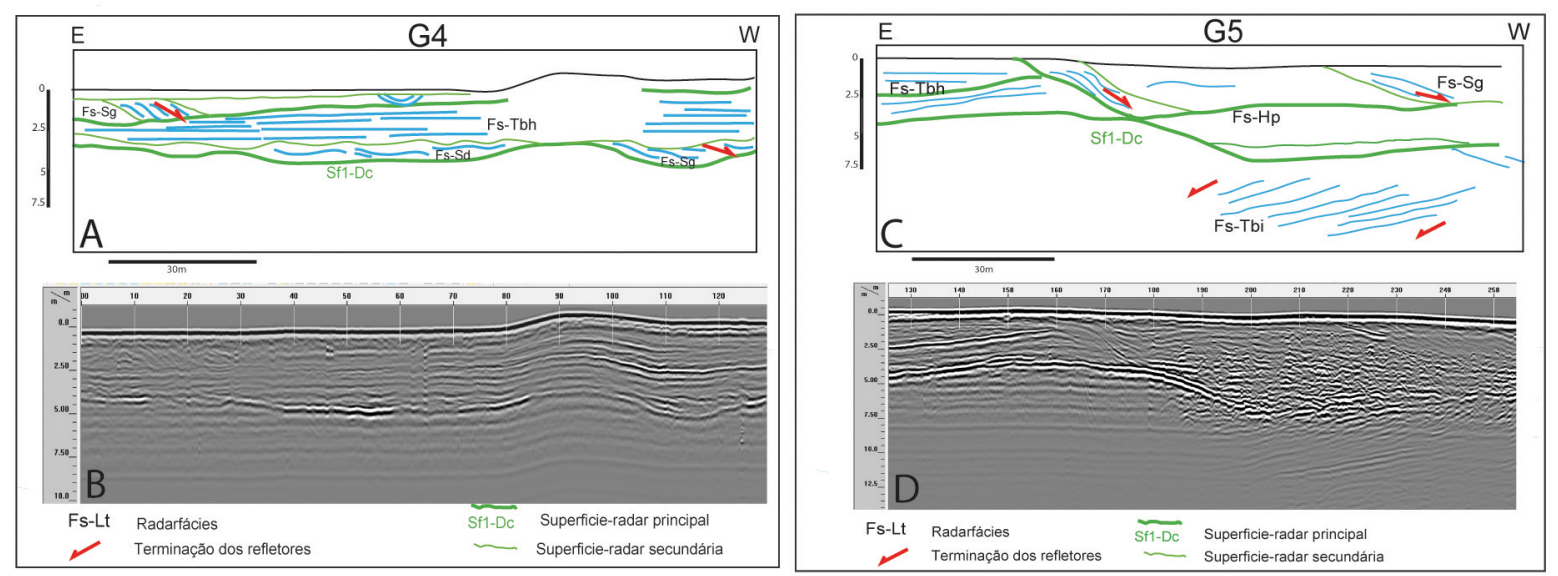

Figura 16. Seção G4 - A) Interpretação dos refletores; B) Radargrama. Seção G5 - C) Interpretação dos refletores; D) Radargrama.

\section{Conclusões}

A constante dielétrica utilizada no levantamento com o georradar foi validada pelos dados dos testemunhos de sondagem, com boa correspondência entre as superfícies de radar e os contatos sedimentares. Também houve concordância entre as radarfácies e os limites das unidades do mapa geológico.

Pelos dados analisados pode-se concluir que no Holoceno Médio existiu na região um sistema barreira-laguna associado a um braço do paleoestuário da Babitonga. Elementos ativos durante a evolução da barreira holocênica teriam sido esporões ou barras arenosas paralelas à linha de costa e recurvadas na região da desembocadura 
do estuário. 0 crescimento destes esporões teria isolado pequenas lagunas durante a progradação da barreira. 0 crescimento destes esporões está provavelmente relacionado a um período de intensa deriva litorânea, como sugerido por Roy et al. (1994) para costas dominadas por ondas sob condições de nível do mar estável ou sob uma queda pouco expressiva.

Agradecimentos - Ao CNPq pelo financiamento dos recursos de campo e laboratório, através dos projetos 472044/2009-5-“Caracterização das barreiras e evolução paleogeográfica da zona costeira entre a Ilha de São Francisco do Sul e a Ilha Comprida," e 472897/2010-1-“Interação entre a dinâmica natural dos ambientes costeiros e as atividades humanas na costa paranaense e norte catarinense", e pelas bolsas em produtividade e pesquisa de MCS, RJA e EGB.

\section{Referências}

Alves, J.H.G.M. 1996. Refração do espectro de ondas em águas rasas: Aplicações para a costa de São Francisco do Sul, SC, Brasil. Florianópolis, 89p. Dissertação de Mestrado. Programa de Pós-graduação em Geografia, Centro de Filosofia e Ciências Humanas, Universidade Federal de Santa Catarina.

Angulo, R.J., Lessa, G.C. \& Souza, M.C. 2006. A Critical Review of Mid- to Late Holocene Sea-level Fluctuations on the Eastern Brazilian Coastline. Quaternary Science Reviews, 25:486-506.

Angulo, R.J., Lessa, G.C. \& Souza M.C. 2009. The Holocene Barrier Systems of the Santa Catarina Coast, Southern Brazil. In: Dillenburg, S.R. \& Hesp, P.A. (eds.), Geology and Geomorphology of Holocene Coastal Barriers of Brazil. Berlim, Springer-Verlag, p.135-172.

Anjos, M.L.M. 2010. Mapeamento Geológico-Geomorfológico da Planície Costeira Quaternária da Ilha de São Francisco do Sul, Sul do Brasil. Curitiba, 109p. Dissertação de Mestrado. Programa de Pós-graduação em Geologia, Universidade Federal do Paraná.

Barboza, E.G., Dillenburg, S.R., Rosa, M.L.C.C., Tomazzelli, L.J. \& Hesp, P.A. 2009. Ground penetrating radar profiles of two Holocene regressive barriers in southern Brazil. Journal of Coastal Research, Special Issue, 56: 579-582.

Barboza, E.G., Angulo, R.J., Souza, M.C., Rosa, M.L.C.C., Stevaux, R.S. \& Ligabue, H.K. 2011. O registro Holocênico em subsuperfície da porção sul da ilha de São Francisco do Sul (SC), Brasil. In: CONGRESSO DA ASSOCIAÇÃO BRASILEIRA DE ESTUDOS DO QUATERNÁRIO, 13, 2011, Armação de Búzios. Anais... ABEQUA, v. 1, p. 56-60.

BNDO. Banco Nacional de Dados Oceanográficos da Marinha Brasileira. 2012. Previsões de marés. Estação Porto de São Francisco do Sul - Delegacia CPSFS (Estado de Santa Catarina). Disponível em: http://
www.mar.mil.br/dhn/chm/tabuas/60220Jan2012. htm. Acesso em: 23 jan. 2012.

Clifton, H.E. 2006. A reexamination of facies models for clastic shorelines. In: Posamentier, H.W. \& Walker, R.G. (eds.), Facies Models revisited. Society for sedimentary research, SEPM Special publication, 84:293-337.

Cury, L.F. 2009. Geologia do Terreno Paranaguá. Curitiba, 187p. Tese de Doutorado. Programa de Pós-graduação em Geologia, Universidade Federal do Paraná.

Davis, J.L. \& Annan, A.P. 1989. Ground-penetrating radar for high resolution mapping of soil and rock stratigraphy. Geophysical Prospect, 3:531-551.

Dillenburg, S.R., Barboza, E.G., Hesp, P.A. \& Rosa, M.L.C.C. 2011. Ground penetrating radar and standard penetration test records of a regressive barrier in southern Brazil. Journal of Coastal Research, 64: 651655.

Fedorova, N. 2001. Meteorologia Sinótica. Pelotas, Editora e Gráfica Universitária UFPel, v. 1, 259 pp. 1999

Fitzgerald, D.M., Cleary, W.J., Buynevich, I.V., Hein, C.J., Klein, A.H.F., Asp, N. \& Angulo, R.J. 2007. Strandplain evolution along the southern coast of Santa Catarina, Brazil. Journal of Coastal Research, 50:152-156.

Fracalossi, F.G., Barboza, E.G., Rosa, M.L.C.C. \& Silva, A.B. 2010. 0 registro em subsuperfície da barreira pleistocênica entre Osório e Tramandaí-RS. Gravel, 8:2131.

Horn Filho, N.O. 1997. O Quaternário costeiro da ilha de São Francisco do Sul e arredores, nordeste de do Estado de Santa Catarina: aspectos geológicos, evolutivos e ambientais. Porto Alegre, 312p. Tese de Doutorado. Programa de Pós-graduação em Geociências, Instituto de Geociências, Universidade Federal do Rio Grande do Sul.

IBGE - Instituto Brasileiro de Geografia e Estatística. 2013. Disponível em: http://www.ibge.gov.br/cidadesat/ Acesso em: 10 mar. 2013.

Jol, H.M. \& Bristow, C.S. 2003. GPR in sediments: advice on data collection, basic processing and interpretation, a good practice guide. In: Bristow, C.S. \& Jol, H.M. (Eds.), Ground Penetrating Radar in Sediments. Geological Society of London Special Publication, p. 9-27.

Martin, L.; Suguio, K.; Flexor, J.M. \& Azevedo, A.E.G. 1988. Mapa geológico do Quaternário costeiro dos Estados do Paraná e Santa Catarina. Brasília, DNPM, Série Geologia, n. 28, 40 p. 2 mapas.

Miall, A.D. 2006. The Geology of Fluvial Deposits: Sedimentary Facies, Basin Analysis and Petroleum Geology. New York, Springer-Verlag, 582p.

Neal, A. 2004. Ground-penetrating radar and its use in sedimentology: principles, problems and progress. Earth-Science Reviews, 66:261-330.

Peel, M.C., Finlayson, B.L. \& Mcmahon, T.A. 2007. Updated world map of the Köppen-Geiger climate classification. Hydrologic and Earth Systems Science, 11:1633-1644.

Possamai, T., Vieira, C.V., Oliveira, F.A. \& Horn Filho, N.O. 2010. Geologia costeira da Ilha de São Francisco do 
Sul, Santa Catarina. Revista de Geografia 2:45-57.

Roy, P.S., Cowell, P.J., Ferland, M.A. \& Thom, B.G. 1994. Wave-dominated coasts. In: Carter, R.W.G. \& Woodroffe, C.D. (eds.) Coastal evolution: late quaternary shoreline morphodynamics. Cambridge University press, p.121-186.

Silva, A.B, Barboza, E.G, Rosa, M.L.C.C. \& Fracalossi, F.G. 2010. Caracterização dos depósitos sedimentares em subsuperfície no setor meridional da Planície Costeira sul de Santa Catarina. Gravel, 8(1)1-7.

Truccolo, E.C. 1998. Maré meteorológica e forçantes atmosféricas locais em São Francisco do Sul - SC. Florianópolis, 100p. Dissertação de Mestrado, Programa de Pós-graduação em Engenharia Ambiental. Universidade Federal de Santa Catarina.

Walker, R.G. 1992. Facies, Facies Models and modern stratigraphic concepts. In: Walker, R.G. \& James, N.P. (Eds.), Facies models: response to sea level change. Geological Association of Canada, p.1-13.

Zular, A. 2011. Sedimentologia e cronologia por luminescência da Ilha de São Francisco do Sul (SC): Considerações sobre a evolução Holocênica de barreiras arenosas da costa sul e sudeste do Brasil. São Paulo, 100p. Dissertação de Mestrado. Programa de Pós-graduação em Geoquímica e Geotectônica. Instituto de Geociências, Universidade de São Paulo.

Man 549

Editores: Tânia M. Strohaecker \& Paulo A. Souza. 
